\title{
The mutual relations between solar activity, thunderstorms and Vertical Gradients of Electro Atmospheric Potential
}

\author{
A. MURri - R. FusARI - C. SCUterini (*)
}

Received on December 4th, 1973

\begin{abstract}
Sumyary. - The mutual relations are established between solar activity expressed in Wolf numbers, the vertical gradient of electro atmospheric potential measured in the Geophysical Observatory of Macerata, the geomagnetic field measured in the Observatory of the nearby town of Aquila, and the thunderstorm activity over the whole of the Italian territory.

The mutual relationship between the vertical gradient, the geomagnetic field and the frequency of thunderstorms and solar activity are clearly evident. In particular the antiparallel behavior between solar activity and the vertical gradient, as well as thunderstorm frequency has been made clear by observations carried out over a period of 22 years.

The results obtained from a study of the geomagnetic field and the vertical gradients agree with the research on a much shorter period of time recently carried out by Rao.

Observational values have been treated as statistical elements $\left({ }^{2}\right)$ to enable smoother readings, without however moving the maximums and minimums of the phenomenon in the given period of time so that parallelisms and antiparallelisms resulting from theso observational values are kept.

The average values of the vertical gradients of electro atmospheric potential were derived for electrically calm days.

From these 5 days per month were chosen by probability method; the averages were then calculated on these five days chosen stochastically. We considered an electrically calm day one in which the sky was absolutely clear, with no thunderstorms either in the vicinity or far from the observatory, with neither fog or haze present.
\end{abstract}

Riassunto. - Vengono stabilite le correlazioni fra attività solare espressa attraverso il numero di Wolf, il gradiente verticale di potenziale elettroatmosferico misurato nell'Osservatorio Geofisico di Macerata, il campo

$\left(^{*}\right)$ Geophysical Observatory, Macerata. 
geomagnetico rilevato nel prossimo Osservatorio della eittì dell'Aquila, la attività temporalesea di tutto il territorio italiano.

Ie correlazioni fra gradiente verticale, campo geomagnetico, frequenza dei temporali ed attività solare appaiono evidenti. In particolare l'andamento antiparallelo fra attività solare e gradiente verticale, come pure con la frequenza dei temporali è messa in evidenza da osservazioni che vertono su di un periodo di 22 anni.

Le considerazioni dell'andamento del campo geomagnetico e del gradiente sono concordanti con quanto recentemente trovato per un periodo assai più breve da Rao.

I valori grez\%i sono stati trattati come elementi statistici $\left(^{2}\right)$ onde avere andamenti più lisei, senza peraltro che i massimi ed i minimi del fenomeno vengano spostati nel tempo, in modo che le condizioni di parallelismo ed antiparallelismo che risultano dai dati grezzi siano perfettamente conservate.

I valori medi del gradiente verticale di potenziale elettroatmosferico sono stati dedotti per i giorni elettricamente calmi. Fra questi sono stati scelti con metodi probabilistici 5 giorni per mese; le medie sono state calcolate su questi cinque giorni prelevati stocasticamente. Per giorno elettricamente calmo è stato scelto quello nel quale il cielo si è presentato assolutamente sereno, non si sono verificati temporali né prossimi all'Osservatorio né lontani, non si sono avute nebbie o foschie.

\section{1. - Preliminary remarks}

In a recent study $\left({ }^{13}\right)$, one of our group expounded the results of research on the behavior of the V.G.E.A.P., also relating it to solar activity expressed by the $R_{z}$ index. On that occasion the correlation values between the two phenomena were calculated, and it was seen that the two presented a definite antiparallel behavior, which was also indicated by the experimental curves.

Only during the presence of disturbing factors in the lower atmosphere, like fall-out caused by a nuclear explosion, did the correlation index denote deflection which was to be attributed to modifications in the electric field caused by the entrance of a large quantity of radioactive particles which resulted in a screening of the electro atmospheric field and consequent interference with its interdependence on solar activity.

Further studies have been made with a wider range of V.G.E.A.P. readings as we extended our research over a period of 22 years including 3 years from cycle $N^{\circ} 18(1944,3-1954,4)$, the whole of cycle $N^{\circ}$ $19(1954,4-1964,8)$ and part of cycle No 20 from 1964,8 up to and including the whole of $1972\left({ }^{23,24}\right)$. 
We also compared the behavior of the geomagnetic field and storm activity over the whole of the Italian territory.

Regarding the representation of solar activity we chose the Wolf numbers for sunspots which, at least as a first approximation, offer an effective measurement of this activity, these numbers were supplied by the observatories at Arcetri, Rome and Catania.

Finally all the observational data was treated statistically to smooth the curves representing the phenomena, without however altering the maximum and minimum positions $\left(^{2,12}\right)$.

As in previous studies, the V.G.E.A.P. was calculated with values taken on electrically calm days. From these days, five were drawn by date, and from them we calculated the average hourly and monthly values. We only intended as suitable days those with fair weather, without any cloud formations, fog or electric disturbances.

\section{2. - Correlation of the V.G.E.A.P. With solar ACTIVITY}

Research on the V.G.E.A.P., begun in 1951 with a quadrant electrometer and then continued with a valve electrometer, enabled the examination of the parameter values over a period of 22 years from 1951 up to 1972 , and this research is still being continued today.

The curves in Fig. 1 illustrate the antiparallelism between solar activity and the V.G.E.A.P. Solar activity being represented by its $\log$ graph. If variations in solar activity are in fact the primary cause of variations in the V.G.E.A.P.; the effect, which is very often in logarithmical relation to the cause and therefore the correlation, should be more apparent with the $\log W_{m}$ (solar activity) curve. In fact this correlation is represented in fig. 1 and the antiparallelism is, we think, quite significant.

To the minimum solar activity recorded in 1954 there corresponds, with marked adherence in time, the V.G.E.A.P. maximum, the latter being one of the highest recorded during the whole period of research.

The solar maximum of 1957 which coincided with the maximum of the 80 years period of solar activity did not apparently determine a major decrease in the V.G.E.A.P., even if comparisons with successive recordings have been rendered quite difficult owing to the fact that during recent years there has been an erosion of daily values and averages of the gradient due to the progressive increase in pol- 
lution in the area where recordings are effected, with consequent alterations in the local electro atmospheric field.

This pollution by markedly increasing the relative humidity and thus favouring the formation of fog and nigh mists, has altered the vertical gradient by lowering its average, as is to be expected since the V.G.E.A.P. is inversely proportional to atmospheric humidity $\left({ }^{0,9,21}\right)$.

The following minimum in solar activity, which extended over a longer period of time than the previous one, is correlated with a much less evident gradient maximum, as is easily seen by the figures in table 1 and illustrated in Fig. 1.

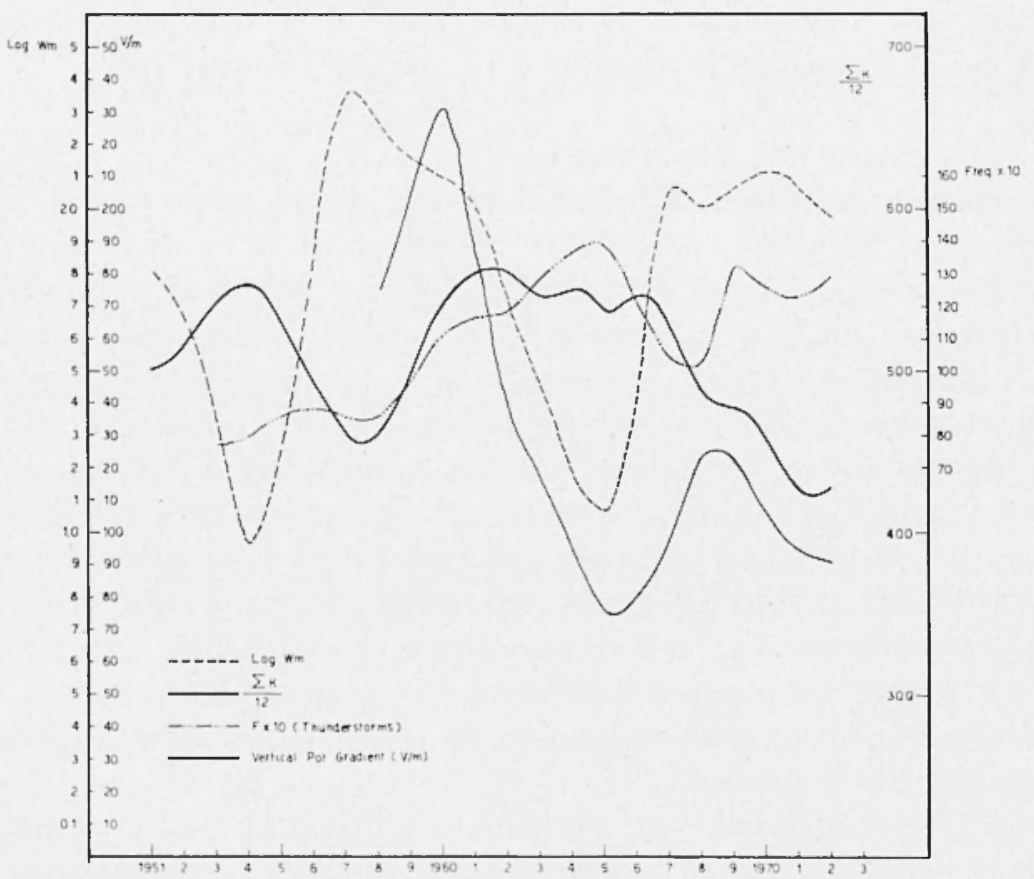

Fig. 1 - The vertical potential gradients smoothing; the geomagnetic field; thunderstorm frequency, and logs of solar activity expressed in Wolf numbers.

The following solar maximum of 1970 was preceded by quite a long period of fluctuating activity which presented a decrease in 1968 and 1969 compared with values reached in 1967. 
It was possible to note yet once again that these variations in solar activity were accompanied by fluctuations in an antiparallel manner in the V.G.E.A.P. even though these fluctuations were limited.

In fact there corresponds to the secondary minimum in solar activity thus formed in 1968, a halt in the gradual decrease in the gradient values with a tendency to return to higher values.

It can also be seen that, while for the solar minimums and maximums recorded in 1954 and 1957 the corresponding minimums and maximums in the gradient appeared during the same period (the time lapse not exceeding 2 months), the following coincidences were slightly displaced in time, as the minimums and maximums of the gradient appeared a few months after the maximums and minimums in solar activity.

This fact can be justified by the seasonal variations of the gradient, which sometimes slightly modify its behavior.

This is what happened during the solar maximum of July 1970 which was followed by the gradient minimum during the last months of that year.

The fluctuations in solar activity also have their influence in establishing a slight time lapse in the coincidence between the maximums and minimums of the two although they still maintain in their general behavior a clearly antiparallel structure.

\section{3. - Correlation With the geomagnetic FIELD}

During our research we also considered the values of the geomagnetic field and its average behavior, which has been illustrated together with the other values in Fig. 1.

The values of this parameter were taken from the bulletin issued by the Aquila Observatory. The field values recorded in Aquila were chosen in consideration of the fact that it is the nearest geomagnetic observatory to our research station.

The behavior of this parameter is already known, presenting, as it does, its maximums and minimums in agreement with those of solar activity. The values at our disposition start from 1958 and clearly state their antiparallel behavior respecting V.G.E.A.P. values. This behavior had already been illustrated by Rao in $1970\left({ }^{25}\right)$ for the same period. 
It can be seen that, although the antiparallelism between the two parameters is maintained, the maximums and minimums of the two phenomena do not always coincide in time, but are separated by variable periods, as has already been noted regarding the solar and V.G.E.A.P. maximums and minimums.

On the other hand this observation, limited to the period considered, can also be applied to the very short periods considered by Rao in this work which we have already quoted.

\section{4. - ComReltion With ThUNDERSTORMS IN ITALiAN Region}

The frequency of thunderstorms over the whole of the Italian territory from 1953 until 1970 has also been considered, and is indicated in Fig. 1. As can easily be seen, the frequency of thunderstorms presents a minimum in relation to the solar maximum of 1957 , a maximum in correspondence with the solar minimum of 1954 and a minimum in relation to the maximum of 1970 .

Therefore we can add that what has already been said regarding the other phenomena examined can also be applied to thunderstorm activity, i.e. the correspondence between thunderstorms and solar activity is marked when the latter is well evidenced, and less noticeable during other periods, as can be seen by the thunderstorm activity $1968 / 1972$.

It is however evident that, during the period considered and in our area the V.G.E.A.P. and thunderstorm activity are correlated in a positive manner with parallel behavior, even if the coincidences in time between the maximums and minimums, as has already been noted, present slight discrepancies.

In a significant recent publication Sarukhanyan and Smirnov (28) have determined the correlation between the atmospheric circulation in the northern hemisphere and solar activity over the past 50 years and reach interesting conclusions, which, we think, confirm what we have discovered regarding thunderstorms.

In fact the two Russian authors determine that the frequency of atmospheric zonal processes in the northern hemisphere decrease with the increasing solar activity during the 11 years cycle, whilst the frequency of these processes increases when the sun's activity diminuishes. 
Since the frequency of zonal processes determines and establishes the formation of thunderstorms, the Russian publication would confirm the antiparallel correlation between the solar cycle and thunderstorm activity, as we have said, or at least this has been so for the past 50 years.

\section{5. - Discussion AND CONCLUSIONS}

From what has been briefly set forth above it can be seen that, in the area of observation from 1951 to 1972, the V.G.E.A.P.; was antiparallel to solar activity, indicated by the number of $W_{m}$ sunspots recorded at the observatories of Arcetri, Catania and Rome.

At the same time, having considered the behavior of the geomagnetic field (measured at the nearby observatory of Aquila) it was noticed that the V.G.E.A.P. and the geomagnetic field (in this area and for the given period of time) could be considered as very near antiparallels, thus confirming what has been discovered by other for shorter periods of time.

Our study of thunderstorm activity, covering the whole of Italy for further precision in determining stormy days, has enabled us to point out the parallelism between thunderstorm activity and the V.G.E.A.P., and that both of these are antiparallel to the solar activity curve as defined above.

On the other hand it is necessary to point out that the authors are well aware that what has been found during their research appears at least partially in opposition to the findings of others $\left({ }^{16,17}\right)$ as for example Bauer, who when considering sunspots from 1902 to 1922 and the behavior of the electric field found a parallelism (19 vol. II - pag. 52) or Brooks who discovered that thunderstorm activity and sunspots during a cycle were parallel, whilst in our research we have found them to be decidedly antiparallel.

According to Russian research workers (Likter I. Ya and coll. written communication to the E.A.'s fourth international conference Tokyo 1968 - quoted by Markson) $\left({ }^{20}\right)$ the antiparallel behavior similar to the one observed by us is typical of the equatorial regions. Rao, already quoted by us, found antiparallel behavior between the V.G.E.A.P. and the geomagnetic field for alpine stations.

The behavior of the V.G.E.A.P. was compared to the polarity of the sunspots (northern hemisphere) and to the sun's poloidal field 
in the various cycles which we considered, and in our opinion there is no immediate correlation between these phenomena.

In conclusion we can add that, continuing our systematic research on the V.G.E.A.P. in our observatory we have during this period, following the maximum solar activity of 1970,8 , noticed a constant and progressive increase, month by month, of the vertical gradient values.

This leads us to suppose that also during the future minimum solar activity, the gradient values will present a relative maximum, thus probably confirming for the solar cycle No 20 the antiparallel behavior already noted during proceding cycles.

\section{BIBIJIOGRAFIA}

(1) Aunrey M.-Cerister Je., 1971. - Le vents solaire. "Sciences", 2, Parigi.

(2) Brooks (. E. P.-Carnutiens N., 1953. - Handbook of statistical methods in Meteorology. (cap. IV - pag. 258), "Met. Office", Luondra.

$\left({ }^{3}\right)$ BEARD D. B., 1967. - The solar wind. Reports on "Progress in Physies", pag. 409, Isondon.

$\left({ }^{3}\right)$ Brooks C. E. P., 1934. - Tariation of the annual frequency of thin. derstorms in relation to sunspots. Quart. "J.R.M.S.", 60, pag. 159-165.

(') Ciratuers A. J., 1967. - Atmospherie Electricity (II ed.). Pergamon Press, Oxford.

$\left({ }^{5}\right)$ Cirapian S.-Bartel.s J., 1962. - Geomagnetism. Vol. I, cap. V/XI Vol. II, cap. XXIV, Oxford Press.

$\left({ }^{8}\right)$ Cовв L. W., 1973. - Oceanic aerosol levels deduced from measurement of the electrical conduclivity of the atmosphere. "Journal of Atmosph. Science", Jan. 30th, pag. 104-106.

(7) Совв IE. W., 1967. - Evidence of a solar infuence on the atmospheric elec. "Elements of Mauna Loa Observatory", montly Weather Review, 95, 12, pag. 905-911.

$\left.{ }^{8}\right)$ Cononiti S.-IIUGins J. - Planetary electrodinamyes proceedings of the If Int. Conf. on the universal aspect of atmosph. elec. Vol. I, pag. 12-5-7 - Vol. II, pag. 1-8-9-10, sez. VIII, pag. 1-3-5, sez. VII.


sevier Pub. Com.ny, Amsterdam.

(10) Dauvititer A., 1960. - Le soleil et la terre. Ed. Palais de la dec.te, Serie $A, n^{\circ} 260$, Paris.

(11) I)auvithien A., 1954. - Le magnetisme des corps célestes. "Physique cosmique", Hermann \& C., III, cap. III, Paris.

(12) I) Esloge A. E., 1966. - Statistical Physics (cap. 9). Holt, Rin. \& Winston Ine, New York. 
(13) Gualtieri G.-Murri A., 1969. - The vertical gradient of electro atm. potential at Macerata (Central East Appennines). "Annali di Geofisica", XXII, l, pag. 33-55, Roma.

(14) Kasemir H. W., 1962. - Does the atmospheric current flow penetrate the jonosphere and outer spaces. "Journal of Geoph. Research", 67, 4.

(15) King J. W.-Newmann W. S. (editors), 1967. - Solar terrestrial physics. Academic Press, Londra.

(16) IANeseldi R., 1969. - Correlazione fra il gradiente di potenziale elet. atm. ed il sole. Relazione al XVIII convegno A.G.I. del 14 Ottobre. Atti "AGI", parte II, Napoli.

(17) IAneseldi R., 1969. - L'attività temporalesca a Tenezia e l'attività solare durante l'undecennio 1959-1969. Atti "AGI", parte I, Napoli.

$\left.{ }^{18}\right)$ Imuanitov I. M.-Cirubarina E. V., 1967. - Electricity of the free atmosphere. (cap. Ill, pag. 3-4-5-6). "Israel Program for Sc. Transl.", Jerusalem.

(19) Israel II., 1961. - Atmospherische Elehtrizität. "Akad. Verlag", I, II, Leipzig.

$\left.{ }^{20}\right)$ MARKson Ralph, 1971. - Considerations regarding solar and lunar modulation of geoph. parameters, atmosph. electricity and thunderstorms. "Pageoph.", 84, pag. 161-202.

(21) MuRri A., 1964. - Caratteristiche del gradiente di potenz. verticale elettroatmosferico a Macerata. "Geofisica e Meteorologia", 13, 1-2, Genova.

${ }^{(22)}$ Ortner J.-MASeland II., 1965. - Introduction to solar terrestrial relations (proceedings of the summer School in space physics - 1963). Reidel Pub. C., Dordrecht (Olanda).

(23) Osservatorio Astrofisico di Catania (Morgante O.-Torrisi S.-D'ArRIGO (.), 1962-1970. - Pubblicazioni nuova serie contenenti le osservazioni solari no 53-63-80-95-106-130-141-144.

(24) Osservatorio Astronomico Universitario, 1950-1970. - Coelum. Annate dal 1950 al 1970 , Bologna.

(25) RAO M., 1970. - On the possible influence of the magnetic activity on the atm. electric parameters. "Journal of the atm. and Terr. Physies", 32, pag. 1431-37.

${ }^{(26)}$ ReIten R. - Further evidence for impact of solar fare on potenlial gradient and air earth current characteristics of High Mountains stations. "Pageoph", pag. 142-157.

(27) ReIter R., 1969. - Solar fare and their impact on potential gradient and air - earth current characteristics at High Mountain stations. "Pageoph", I, pag. 209-272.

${ }^{28}$ ) SARUKIIANYAN E. I.-SMIRnov N. P., 1970. - Solar activity, earth's pressure field and atmospheric circulation. "Geomagnetism and Aeronomy", $\mathrm{X}, 3$, pag. 390 .

${ }^{(20)}$ ScImmering E. R., 1966. - Advances in ionospheric physics in the Rocket and Salellites Era. "Reviews of Geophysics", 4, 3, (Febbraio), pag. 329 362. 